\title{
Treatment and outcome of neonates with hypoxic ischaemic encephalopathy at B.P. Koirala Institute of Health Sciences
}

\author{
*Jyoti Agrawal ${ }^{1}$, Satish Yadav ${ }^{1}$, Shipra Chaudhary', Shyam Prasad Kafle ${ }^{1}$ \\ Sri Lanka Journal of Child Health, 2017; 46(2): 128-132
}

\begin{abstract}
Introduction: Perinatal asphyxia is an important cause of neonatal deaths and neonatal intensive care unit (NICU) admission.
\end{abstract}

Objectives: To assess the treatment pattern in neonates having hypoxic ischaemic encephalopathy (HIE) and its relationship with their outcome.

Method: A hospital based prospective study of one year duration was carried out at B.P. Koirala Institute of Health Sciences, Nepal in term neonates with perinatal asphyxia and HIE, enrolled from the paediatric wards and NICU.

Results: Of the 60 term neonates included in the study, $49(81.7 \%)$ were males. The mean birth weight was $2971 \pm 421 \mathrm{~g}$. HIE was mild in 13 $(21.7 \%)$ cases, moderate in $27(45 \%)$ cases and severe in $20(33.3 \%)$ cases. Seventeen neonates were admitted to the NICU. Oxygen was required in 45 neonates (mean duration 60.3 hours). Mechanical ventilation and vasopressors were given in 13 and 29 neonates respectively. Most of the neonates received antibiotics for 5 days. Mean duration of hospital stay was 146.2 hours. Thirteen $(21.7 \%)$ neonates were neurologically abnormal at discharge. Forty one $(68 \%)$ neonates were discharged from hospital, $06(10 \%)$ expired during the hospital stay and 7 left against medical advice.

Conclusions: In this study at the B. P. Koirala Institute of Health Sciences, 22\% neonates with perinatal asphyxia and HIE were neurologically abnormal at the time of discharge and there was a $10 \%$ mortality.

DOI: http://dx.doi.org/10.4038/sljch.v46i2.8268

(Key words: Perinatal asphyxia, hypoxaemic ischaemic encephalopathy)

\footnotetext{
${ }^{1}$ B.P. Koirala Institute of Health Sciences, Nepal

*Correspondence: jyoti_doctor@yahoo.com

(Received on 10 July 2016: Accepted after revision on 26 August 2016)

The authors declare that there are no conflicts of interest

Personal funding was used for this project.

Open Access Article published under the Creative

Commons Attribution CC-BY CC ${ }_{\mathrm{BY}}$ License.
}

\section{Introduction}

There are more than 9 million deaths annually during the perinatal and neonatal periods, most deaths occurring in developing countries ${ }^{1}$. Each year around 4 million babies are born asphyxiated of whom 1 million die and one million suffer severe neurological complications such as cerebral palsy, mental retardation or epilepsy ${ }^{2}$. Hypoxic ischaemic encephalopathy (HIE) in an asphyxiated neonate can lead to serious long-term problems among survivors ${ }^{3}$. Perinatal asphyxia has an incidence of $0.5-2 \%$ of live births ${ }^{4,5}$. It accounts for $30 \%$ neonatal deaths in Nepal ${ }^{6}$. Perinatal asphyxia is an important cause of multiorgan dysfunction ${ }^{7}$.

\section{Objectives}

To assess the treatment pattern in neonates having hypoxic ischaemic encephalopathy (HIE) and its relationship with their outcome.

\section{Method}

A prospective observational study was carried out at B.P. Koirala Institute of Health Sciences (BPKIHS) in eastern Nepal from February 2013 to January 2014. The study was approved by the BPKIHS Ethics Committee and prior written informed consent was obtained from the parents or guardian of the neonates. Term babies delivered at BPKIHS, who developed perinatal asphyxia and HIE, in accordance with Levene staging ${ }^{8}$ comprised the study population. APGAR scores were assessed at 1,5 and 10 minutes and resuscitation was carried out in line with the 2005 Neonatal Resuscitation Programme (NRP) guidelines of the American Heart Association and American Academy of Paediatrics ${ }^{9}$. Babies with congenital heart disease, central nervous system abnormalities or sepsis were excluded from the study.

All babies were managed in the neonatal intensive care unit (NICU) according to the hospital protocol which included administration of oxygen, nasal continuous positive airway pressure (NCPAP), mechanical ventilation, intravenous fluids, vitamin $\mathrm{K}$, inotropes and anticonvulsants as needed. Cefotaxime and gentamycin were given to babies at risk of sepsis and to babies requiring mechanical ventilation. Once babies improved, orogastric feeding was started followed by spoon or breast feeding. An electrocardiogram (ECG) was done and $4 \mathrm{ml}$ of venous blood was taken from each neonate within 72 hours of life for routine 
haematological and biochemical investigations and cardiac enzyme estimation. A chest X-ray was done in all babies. Along with all the demographics, the investigations, treatment and outcome were noted in a predesigned proforma.

Data were entered in an Excel sheet for analysis. Analysis of Variance (ANOVA) was used to compare the differences in mean of quantitative data among different stages of HIE and Chi-Square test was used to compare proportions.

\section{Results}

Sixty term neonates with HIE were enrolled into the study within 72 hours after birth. Of them, 43 $(71.7 \%)$ neonates required active resuscitation. Of the 43 neonates, 41 required only bag and mask ventilation whilst 2 with severe HIE required endotracheal tube ventilation and chest compressions. Birth details are shown in Table 1.

Table 1: Birth details

\begin{tabular}{|l|c|c|c|c|}
\hline \multicolumn{1}{|c|}{ Birth details } & \multicolumn{2}{c|}{ HIE stage } & P value \\
\hline Resuscitation & 1 (mild) & & 3 (severe) & \\
Not needed & & 13 & 01 & 0.009 \\
Needed & 03 & 14 & 19 & \\
$\quad$ Bag and Mask & 10 & 14 & 2 & \\
Endotracheal tube & 10 & 0 & 2 & \\
Chest compressions & 0 & 0 & & \\
\hline Apgar score & 0 & $3.11 \pm 0.64$ & $2.55 \pm 0.6$ & $<0.001$ \\
at 1 minute & $3.23 \pm 0.83$ & $4.78 \pm 0.58$ & $4.1 \pm 0.79$ & $<0.001$ \\
at 5 minutes & $5.08 \pm 0.49$ & $6.96 \pm 0.9$ & $5.5 \pm 1.15$ & \\
at 10 minutes & $7.46 \pm 0.88$ & & & \\
\hline
\end{tabular}

According to HIE staging, $13(21.7 \%)$ neonates were in mild, 27 (45\%) neonates were in moderate and $20(33.3 \%)$ neonates were in severe HIE groups (Table 1).

The Apgar score at 1 minute was less than 3 in 14 patients with a mean Apgar at 1 minute of 2.95. Apgar score at 5 minutes was more than 5 in 3 $(5 \%)$ newborns and 3-5 in $57(95 \%)$ none of them having a score of less than 3. Similarly, mean Apgar scores at 5 and 10 minutes were 4.62 and 6.58 respectively. The mean Apgar scores at 1 minute, 5 minutes and 10 minutes were statistically significant among different stages of HIE as shown in Table 1.

The treatment details of neonates with HIE are shown in Table 2.

Table 2: Treatment details of neonates with HIE

\begin{tabular}{|l|c|c|}
\hline Treatment detail & Number (\%) & Mean \pm SD \\
\hline Oxygen through Head box (hours) & $19(42.2)$ & \\
$<48$ & $20(44.5)$ & $60.27 \pm 54.81$ \\
$48-96$ & $06(13.2)$ & \\
$97-240$ & $08(47.1)$ & \\
\hline Oxygen through nasal continuous positive airway pressure (hours) & $07(41.1)$ & $25.88 \pm 21.96$ \\
$<24$ & $01(11.8)$ & \\
$24-48$ & $11(64.7)$ & $20.25 \pm 23.46$ \\
$>48$ & $06(35.3)$ & \\
\hline Bag and tube ventilation (hours) & $01(07.6)$ & \\
$<24$ & $06(46.2)$ & $89.15 \pm 62.23$ \\
$24-72$ & $06(46.2)$ & \\
\hline Mechanical ventilation (hours) & $29(48.3)$ & \\
$<24$ & $31(51.7)$ & \\
$24-72$ & $06(20.7)$ & \\
$>72$ & $09(31.0$ & $103.24 \pm 70.57$ \\
\hline Vasopressors & $14(48.3)$ & \\
Present & & \\
Absent & & \\
\hline Duration of vasopressors (hours) & & \\
$<48$ & & \\
$48-96$ & & \\
$>96$ & & \\
\hline
\end{tabular}


As shown in Table 2, forty five neonates required oxygen through head box, 17 required bag and tube ventilation 13 required mechanical ventilation and 29 required vasopressors. Antibiotics were given in
56 neonates, $60.7 \%$ receiving them for 5 or less days. Mean duration of antibiotics was 6.1 days.

Table 3 shows the univariate analysis of treatment details.

Table 3: Univariate analysis of treatment details

\begin{tabular}{|l|c|c|c|c|}
\hline \multicolumn{1}{|c|}{ Treatment } & \multicolumn{2}{c|}{$\begin{array}{c}\text { HIE stage } \\
\text { Moderate }\end{array}$} & Severe & P value \\
\hline Anticonvulsants & & & & \\
No & 13 & 0 & 07 & $<0.001$ \\
Yes & 0 & 27 & 13 & \\
\hline $\begin{array}{l}\text { Vasopressors } \\
\text { Given }\end{array}$ & 0 & 09 & 20 & $<0.001$ \\
Not given & 13 & 18 & 0 & \\
\hline $\begin{array}{l}\text { Antibiotics } \\
\text { Given }\end{array}$ & 09 & 27 & 20 & $<0.001$ \\
Not given & 04 & 0 & 0 & \\
\hline Number of anticonvulsants & 0 & $1.11 \pm 0.32$ & $1.15 \pm 0.38$ & 0.934 \\
\hline Oxygen head box (hours) & $48.85 \pm 61.78$ & $64.56 \pm 51.35$ & $66.14 \pm 58.72$ & 0.681 \\
\hline Continuous positive airway pressure (hrs) & $7.25 \pm 3.59$ & $29.00 \pm 15.10$ & $32.78 \pm 25.34$ & 0.146 \\
\hline Bag and tube ventilation (hours) & $3.1250 \pm 4.0659$ & $4.3333 \pm 2.5166$ & $7.0833 \pm 4.9926$ & 0.181 \\
\hline Mechanical ventilation(hours) & 0 & $48.00 \pm 0.00$ & $92.58 \pm 63.70$ & 0.818 \\
\hline Duration of vasopressors(hours) & 0 & $98.78 \pm 42.35$ & $105.25 \pm 81.05$ & 0.976 \\
\hline Duration of antibiotics (days) & $5.89 \pm 3.22$ & $6.00 \pm 2.02$ & $6.30 \pm 5.07$ & 0.944 \\
\hline
\end{tabular}

As shown in table 3 on univariate analysis, requirements of anticonvulsants, vasopressors and antibiotics were significantly associated with HIE stages. However, the number of anticonvulsants required, duration of oxygen by head box, duration of continuous positive airway pressure, duration of bag and tube ventilation, duration of mechanical ventilation and duration of vasopressors and antibiotics were not statistically significant in relation to HIE stages.

In-patient management regarding feeding and use of intravenous fluid is shown in table 4.

Table 4: Outcome of babies in relation to feeding and intravenous fluid

\begin{tabular}{|l|c|c|}
\hline \multicolumn{1}{|c|}{ Outcome } & Number (\%) & Mean \pm SD \\
\hline Start of nasogastric feeding (hours) & $02(04.5)$ & \\
$<48$ & $30(68.2)$ & $103.57 \pm 59.49$ \\
$48-96$ & $12(27.3)$ & \\
$>96$ & $02(04.8)$ & \\
\hline Start of breast feeding (hours) & $17(40.8)$ & $145.33 \pm 94.30$ \\
$<48$ & $18(42.9)$ & \\
$48-96$ & $05(11.9)$ & \\
$97-240$ & $04(06.7)$ & $131.63 \pm 85.53$ \\
$>240$ & $26(43.3)$ & \\
\hline Intravenous fluid (hours) & $25(41.7)$ & \\
$<48$ & $05(08.3)$ & \\
$48-96$ & & \\
$97-240$ & & \\
$>240$ & & \\
\hline
\end{tabular}

Seventeen neonates needed NICU care. Out of them, $06(35.3 \%)$ were in NICU for 48-96 hours and other 06 neonates for 97-240 hours with a mean duration of $118.94 \pm 105.90$ hours of NICU stay.
The duration of hospital stay was less than 48 hours in $03(5 \%)$ babies, $48-96$ hours in $15(25 \%)$ babies, $97-240$ hours in $37(61.6 \%)$ babies and more than 240 hours in $05(8.3 \%)$ babies. The mean duration of hospital stay was $146.17 \pm 91.3$ hours. The condition at discharge is shown in Table 5. 
Table 5: Condition at discharge

\begin{tabular}{|l|c|c|c|c|}
\hline \multirow{2}{*}{ Treatment } & \multicolumn{3}{|c|}{ HIE Stage } & P value \\
\cline { 2 - 4 } & Mild & Moderate & Severe & \\
\hline Outcome & 0 & & & \\
Death & 12 & 0 & 06 & \\
Discharge & 01 & 02 & 04 & $<0.001$ \\
Left against medical advice & 12 & 25 & 10 & \\
\hline Final Outcome & 01 & 02 & 04 & $<0.001$ \\
Discharged & 0 & 10 & 03 & \\
Death/ Left against medical advice & 12 & 15 & 01 & \\
\hline Anticonvulsant at discharge & 0 & 10 & & \\
Given & 12 & 15 & 0.007 & 0.007 \\
Not given & $123.85 \pm 73.7$ & $154.48 \pm 60.62$ & $154.15 \pm 130.16$ & 0.575 \\
\hline Neurological outcome & $2666.67 \pm 432.93$ & $2937.2 \pm 482.39$ & $2518.75 \pm 367.07$ & 0.111 \\
Abnormal & & & & \\
Normal & & & \\
\hline Hospital stay (hours) & & & \\
\hline Discharge weight(g) & & & & \\
\hline
\end{tabular}

As shown in this table, forty one neonates were discharged, 06 expired and 13 neonates left against medical advice (LAMA). Overall mortality was $10 \%$. When the final outcome in regards to discharged and death/ LAMA was analysed by univariate analysis in different HIE stages they were found to be highly significant. Anticonvulsants at discharge and neurological outcome were also significantly related to HIE stage. However, mean duration of hospital stay and mean discharge weight were not significantly related to HIE stage

\section{Discussion}

In the present study 60 neonates with HIE were enrolled. Demographic data such as gender, neonatal weight, crown rump length, head circumference, maternal registration status, gestational age, antenatal complications, obstetric problems, maternal age, and maternal weight were evenly distributed in the different HIE groups. Mean duration of hospital stay was 146.2 hours. Forty one neonates improved, 06 expired and 13 neonates who were critically ill left against medical advice due to financial constraints. When the final outcome of discharge and death/LAMA was analysed by univariate analysis in different HIE stages, it was found to be highly significant. HIE severity was significantly associated with outcome. Those with severe HIE required more inotropes and anticonvulsants and were on longer duration on mechanical ventilation.

In the study by Shah $\mathrm{P}$ et al, the Apgar score at 5 minutes was less than 5 in $63 \%$ infants ${ }^{7}$. In the study by Martin-Ancel et al, Apgar score at 1 minute was 3 or less in $30 \%$ infants but the Apgar score at 5 minute 3 or less in $14 \%$ infants $^{10}$. In our study, the Apgar score at 1 minute was less than 3 in $23 \%$ and $3-5$ in $77 \%$ patients whilst the Apgar score at 5 minutes was more than 5 in $5 \%$ infants and 3 to 5 in $95 \%$. In the study by Padayachee $\mathrm{N}$ et al., the overall survival rate was $86.7 \%$ with $79.6 \%$ having normal development ${ }^{11}$. In our study the overall survival rate was $68 \%$ and $78.3 \%$ had normal development.

\section{Conclusions}

In this study at B. P. Koirala Institute of Health Sciences $22 \%$ neonates with perinatal asphyxia and HIE were neurologically abnormal at the time of discharge and there was a $10 \%$ mortality.

\section{Acknowledgements}

Authors thank Mr D. Baral, for help in statistical analysis and B. P. Koirala Institute of Health Sciences for providing a research grant for the study.

\section{References}

1. Hoque $M$, Haaq $S$, Islam R. Causes of neonatal admissions and deaths at a rural hospital in KwaZulu-Natal, South Africa. South African Journal of Epidemiology and Infection 2011; 26(1):26-29.

2. Lawn JE, Manandhar A, Haws RA, Darmstadt GL. Reducing one million child deaths from birth asphyxia - a survey of health systems gaps and priorities. Health Research Policy and Systems 2007; 5(1):4. https://doi.org/10.1186/1478-4505-5-4 PMid: 17506872 PMCid: PMC1888686

3. Agarwal R, Jain A, Deorari AK, Paul VK. Post-resuscitation management of asphyxiatedneonates. Indian Journal of Paediatrics 2008; 75:85-90. https://doi.org/10.1007/s12098-008-00265 
4. Hansen AR, Soul JS. Manual of Neonatal Care. $7^{\text {th }}$ ed. Philadelphia (USA): Wolters Kluwer; 2012. P. 711-26.

PMid: 23012770

5. Flores-Nava G, EchevarríaYbarguengoitia JL, Navarro-Barrón JL, García-Alonso A. Transient myocardial ischaemia in newborn babies with perinatal asphyxia (hypoxic cardiomyopathy). Bol Med Hosp Infant Mex 1990; 47:809-13.

PMid: 2098033

6. Lee ACC, Mullany LC, Tielsch JM, et al. Risk factors for neonatalmortality due to birth asphyxia in Southern Nepal. A Prospectivecommunity-based cohort study. Pediatrics 2008; 121:1381-90. https://doi.org/10.1542/peds.2007-1966 PMid: 18450881 PMCid: PMC2377391

7. Shah P, Riphagen S, Beyene J, Perlman M: Multiorgan dysfunction ininfants with post-asphyxial hypoxic-ischaemic encephalopathy. Archives of Disease in Childhood Fetal Neonatal Edition 2004; 89:152-5.

https://doi.org/10.1136/adc.2002.023093

PMCid: PMC1756028
8. Levene MI, Kornberg J, Williams THC. The incidence and severity of postasphyxial encephalopathy in full-term infants. Early Human Development 1985; 11:21-8.

https://doi.org/10.1016/03783782(85)9011 $5-\mathrm{X}$

9. Neonatal Resuscitation Programme Guidelines: Neonatal Resuscitation Manual. American Heart Association and American Academy of Paediatrics; 2005.

10. Martin-Ancel A, Garcia-Alix A, Gaya F, Cabanas F, Burgueros M, Quero J. Multiple organ involvement in perinatal asphyxia. Journal of Pediatrics 1995; 127:786-93.

https://doi.org/10.1016/S00223476(95)701 74-5

11. Padayachee N, Ballot DE. Outcomes of neonates with perinatal asphyxia at a tertiary academic hospital in Johannesburg, South Africa. South African Journal of Child Health 2013; 7(3):89-94. https://doi.org/10.7196/sajch.574 